\title{
Salud mental y discriminación por razones de género en el marco del aborto terapéutico en el Perú(*)
}

\author{
Mental health and gender discrimination in the context of therapeutic \\ abortion in Peru
}

Dessiré Nalvarte Cuzcano(**)

Perú - Pontificia Universidad Católica del Perú.

\begin{abstract}
Resumen: El artículo desarrolla un enfoque de investigación descriptivo sobre un caso particular denunciado ante el INDECOPI, debido a que una clínica no evaluó la salud mental de una mujer gestante ni tramitó correctamente su solicitud de aborto terapéutico en el año 2015, así como que habría sido discriminada por razones de género. En ese sentido, el objetivo es analizar si jurídicamente, en nuestro país, existe la obligatoriedad de evaluar la salud mental de la gestante y qué deberá entenderse como "mal grave y permanente a la salud", tal y como se encuentra contemplado en los dispositivos legales concernientes. Además, determinar el alcance de la discriminación por razones de género en el ámbito mercantil y cómo los estereotipos de género del personal médico conllevaron a negar el servicio solicitado que ameritaba el estadio médico de la gestante.
\end{abstract}

Palabras clave: Aborto Terapéutico - Salud Mental - Discriminación por Razones de Género - Derechos Fundamentales

\begin{abstract}
The article develops a descriptive research approach on a 2015 particular case reported to INDECOPI because a clinic did not evaluate the mental health of a pregnant woman and correctly processed her request for therapeutic abortion, as well as that she would have suffered gender discrimination. Therefore, it is analyzed whether legally, in our country, there is an obligation to evaluate the mental health of the pregnant woman and what should be understood as "serious and permanent health damage", as it is contemplated in the legal devices. This document also develops gender discrimination in the commercial sphere and how gender stereotypes of the medical personnel led to denying the requested service that merited the medical stage of the pregnant woman.
\end{abstract}

Key words: Therapeutic Abortion - Mental health - Gender Discrimination - Fundamental Rights

$\left.{ }^{*}\right) \quad$ Nota de Editor: este artículo fue recibido el día 13 de octubre de 2019 y su publicación fue aprobada el 30 de octubre de 2019.

${ }^{* *}$ Bachillera en Derecho por la Pontificia Universidad Católica del Perú Estudios en Derecho Administrativo, Género y Derecho internacional de los Derechos Humanos. Secretaria técnica de la Comisión Especial para la intervención frente al Hostigamiento Sexual en la Pontificia Universidad Católica del Perú. Secretaria técnica de la Comisión Especial Permanente para la intervención frente al Hostigamiento Sexual de la Universidad Peruana Cayetano Heredia. Contacto: dessire.nalvarte@pucp.pe 


\section{Introduc ción}

Tras peligrosas complicaciones durante el embarazo de la señora Vanessa Borgoño durante los meses de octubre, noviembre y diciembre del 2014, atendidas en la clínica El Golf y tras el diagnóstico de amenaza de aborto, embarazo de alto riesgo quirúrgico y alteración cromosómica del feto de síndrome de Turner; el médico tratante, doctor Almeyda, indicó a la paciente que su gestación no era pasible de ser interrumpida por razones clínicas.

No obstante, luego de ser evaluada externamente por la psiquiatra Marta Rondón, esta concluyó que el embarazo ponía en riesgo la salud mental de la paciente. Asimismo, otro establecimiento clínico le diagnosticó alta probabilidad de cromosomopatía y mal pronóstico perinatal que ponía en riesgo su salud física. De este modo, la paciente decidió solicitar a la clínica el procedimiento de aborto terapéutico establecido por la "Guía Técnica Nacional para la estandarización del procedimiento de la Atención de la gestante en la interrupción Voluntaria por Indicación Terapéutica del Embarazo menor de 22 semanas con consentimiento informado en el marco de los dispuesto en el artículo 119 del Código Penal". Sin embargo, dicha institución decidió no remitir la solicitud al médico tratante y fue respondida luego de 145 días.

Ante ello, tras la negativa del médico tratante y la falta de respuesta la señora Borgoño, tuvo que someterse a un aborto terapéutico en otro establecimiento con aproximadamente 15 semanas de gestación. Es por eso que decidió denunciar a la clínica El Golf ante el INDECOPI el 27 de mayo de 2015, entre otros, por habérsele negado el aborto terapéutico y por discriminarla por razones de género. El 20 de junio de 2017 la autoridad administrativa decidió sancionarla con una multa de 20 UIT por la infracción de los artículos 18, 19 y 67 numeral 1 del Código de Protección y Defensa del Consumidor (en adelante, CPDC), en el extremo referido a no haber tramitado debidamente la solicitud de aborto terapéutico presentada por la denunciante.

\section{2. ¿Qué debe entenderse como Salud Mental en el Perú?}

La autoridad administrativa en la Resolución 1884-2017/ SPC-INDECOPI resolvió sancionar a la clínica, porque ésta debió derivar la solicitud de fecha 18 de diciembre de 2014 (con el diagnóstico de la psiquiatra) para que el doctor Almeyda evalúe si el embarazo de la denunciante causaba un grave y permanente daño a su salud mental, tal y como concluyó la psiquiatra Rondón. En ese sentido, la sancionó por incumplimiento de los artículos 18, 19 y 67.1 del CPDC.

De ello podemos evaluar dos hechos relevantes; primero que, si bien la autoridad consideró que la clínica no actuó razonablemente porque no trasladó al médico los documentos remitidos por la paciente, la autoridad no se percató que la obligatoriedad recaída en la clínica era la de evaluar la salud mental de la señora Borgoño y no que ésta acuda a otra entidad y luego solicitar la interrupción de embarazo.

Como segundo hecho, observamos que la autoridad consideró que el doctor Almeyda debió realizar una suerte de confirmación sobre el diagnóstico de la psiquiatra Rondón, pues concluyó que la Clínica debió alcanzarle el documento con el diagnóstico para que "evalúe" con ello, si correspondía o no, activar el procedimiento de la Guía Técnica.

Vemos que la salud mental de una mujer gestante primero, no fue considerada al momento de evaluar la posibilidad de un aborto terapéutico y, segundo, que, incluso habiendo un diagnóstico clínico sobre la afectación a ella, no fue suficiente porque debió haber una revisión de un médico que evalúa la salud física de la mujer gestante, para que se sustente una intervención.

En ese sentido, analizaremos si la clínica se encontraba obligada a evaluar la salud mental de la gestante para concluir si es que su caso amerita la interrupción del embarazo. Y segundo, si es que el diagnóstico de afectación en la salud mental de la gestante es suficiente por sí misma para la intervención.

Pero antes de tratar estos puntos, es preciso señalar qué es lo que señala expresamente la Guía Técnica respecto a la finalidad de su propia implementación:

\footnotetext{
"Asegurar la Atención Integral de la gestante en los casos de Interrupción Voluntaria por indicación Terapéutica del Embarazo menor de veintidós (22) semanas con consentimiento informado, cuando es el único medio para salvar la vida de la gestante o para evitar en su salud un mal grave y permanente, en el marco de los derechos humanos, con enfoque de calidad, género e interculturalidad".
}

Asimismo, su objetivo se ciñe a lo siguiente:

“Estandarizar los procedimientos para la
atención integral de la gestante en los casos
de Interrupción Voluntaria por Indicación
Terapéutica del Embarazo menor de veintidós 
(22) semanas con consentimiento informado, cuando es el único medio para salvar la vida de la gestante o para evitar en su salud un mal grave y permanente, conforme dispone el artículo 119 del Código Penal y normas legales vigentes".

Ante ello, podemos apreciar que la Guía Técnica está dedicada a dirigir la puesta en práctica del contenido señalado en el artículo 119 del Código Penal, es decir, dado que la interrupción voluntaria del embarazo por razones médicas no es punible, debía darse sentido a los alcances de esta posibilidad jurídica, debido a que es la única que se encuentra exenta de persecución y sanción penal. Asimismo, vemos algo evidente, y es que este protocolo está guiado, expresamente, a salvaguardar la vida y la salud de la mujer gestante.

Recordemos que el artículo 119 del Código Penal señala a la letra:

"No es punible el aborto practicado por un médico con el consentimiento de la mujer embarazada o de su representante legal, si lo tuviera, cuando es el único medio para salvar la vida de la gestante o para evitar en su salud un mal grave y permanente".

Ahora bien, observando las causales permitidas por la Guía Técnica, tenemos una lista de 11 entidades clínicas ante los cuales los médicos tratantes deberán actuar y comunicar a la gestante el peligro en el cual se encuentra. Las 10 primeras entidades son puntualmente, complicaciones en la salud física como, por ejemplo, hipertensión arterial crónica y evidencia de daño de órgano blando o lupus, diabetes o neoplasia maligna. Sin embargo, lo que nos apremia en esta evaluación es lo dispuesto en el numeral 11, el cual señala lo siguiente:

"Sobre la base de lo consensuado por sociedades médicas del Perú se consideran las siguientes entidades clínicas de la gestante, en las que se amerita evaluar la interrupción terapéutica del embarazo: (...)

11. Cualquier otra patología materna que ponga en riesgo la vida de la gestante o genere en su salud un mal grave y permanente, debidamente fundamentada por la Junta Médica."

De este modo, tenemos que analizar a qué se refiere el dispositivo legal cuando señala que la aplicación del aborto terapéutico procederá cuando es el único medio para salvar la vida de la gestante o evitar en su salud un mal grave y permanente. Ello porque se advierte que el contenido es general y abierto a interpretaciones. Además, de una simple lectura, se puede colegir que dependerá enteramente, del criterio médico para encausar cualquier otra entidad médica de la gestante en el numeral 11. Y justamente, es la única causal en donde podría entrar la evaluación a la salud mental.

$Y$ es en este punto en donde debe sentarse las bases de la aplicación de esta causal, porque a lo largo de todos estos años, desde la entrada en vigencia del artículo 119 del Código
Penal en el año 1924 hasta la actualidad, no es claro el alcance del concepto "salud" ni del supuesto "amenaza de daño grave o permanente".

Comencemos entonces por el concepto de salud. Para ello nos apoyaremos en lo dispuesto por nuestra Constitución, precisamente, en el artículo 1, donde afirma que "la defensa de la persona humana y el respeto de su dignidad son el fin supremo de la sociedad y del Estado; en el artículo 2, que reconoce el derecho de toda persona a la integridad "moral, psíquica y física"; en el artículo 7, cuando señala que todos tienen derecho a la protección de su salud; y, por último, en el artículo 13, que dispone que la protección del derecho a la salud se plantea como un principio rector de la política pública, social y económica del Estado, que se ejecuta a través del Poder Ejecutivo, el cual a su vez se encarga de diseñar, normar y supervisar su aplicación en forma plural y descentralizada.

Por su parte, la salud también se encuentra reconocida en las fuentes normativas del Derecho Internacional de los Derechos Humanos. Así, según el artículo 12 del Pacto Internacional de Derechos Económicos, Sociales y Culturales, toda persona tiene derecho al "disfrute del más alto nivel posible de salud física y mental". Por otro lado, el

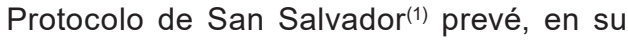
artículo 10 que toda persona tiene derecho a la salud, entendida como el disfrute del más alto nivel de bienestar físico, mental y social.

Al respecto, los tratados internacionales que un Estado ratifica son de obligatorio cumplimiento, pues este se ha conminado a cumplirlos de manera voluntaria. Ello lo señala la Convención de Viena de 1969 sobre el Derecho de los Tratados, precisamente, en sus artículos 26 y 27 que indican que todo tratado en vigor obliga a las partes, y debe ser cumplido por ellas de buena fe (Pacta sunt servanda), y que un Estado no puede invocar las disposiciones de su derecho interno para incumplir un tratado.

Recordemos que en nuestra Constitución en el artículo 55, justamente, se encuentra recogido que los tratados celebrados por el

(1) El Protocolo de San Salvador completa la Convención Americana de Derechos Humanos. 
Estado peruano y en vigor forman parte del derecho nacional. Asimismo, en su Cuarta Disposición Final y Transitoria se estipula que los derechos y libertades reconocidos en la Constitución deben interpretarse de conformidad con los tratados ratificados por el Perú.

Es por ello que, el Tribunal Constitucional (en adelante, TC) en el año 2006 ha establecido que el contenido de los tratados sobre derechos humanos tiene rango constitucional, indicando que estos prevalecerán sobre las normas con rango de ley y las demás normas de menor jerarquía. Asimismo, ha señalado que estos tratados no solo forman parte del ordenamiento nacional, sino que los poderes públicos deben incorporar dentro del contenido constitucionalmente protegido de los derechos, a los ámbitos normativos de los derechos humanos reconocidos en los tratados. Finalmente, señaló que, todo organismo público debe observar y considerar obligatoriamente la interpretación que hayan realizado los tribunales internacionales de los tratados de derechos humanos de los que Perú es parte ${ }^{(2)}$.

Ahora bien, nuestro TC también ha señalado en una sentencia del 2008 que, el derecho a la salud en su dimensión de libertad implica la facultad inherente a todo ser humano de conservar un estado de normalidad orgánica funcional, tanto física como psíquica y social, así como de prevenirlo y restituirlo ante una situación de perturbación. Es decir, garantiza el derecho de las personas a alcanzar y preservar un estado de plenitud física, psíquica y social, razón por la cual el Estado debe efectuar acciones de prevención, conservación y restablecimiento, con la finalidad de que todas las personas disfruten del más alto nivel de bienestar físico, mental y social, para que tengan, cada día, una mejor calidad de vida, y ello porque el concepto de persona humana comprende aspectos tanto materiales, físicos y biológicos, como espirituales, mentales y psíquicos ${ }^{(3)}$.

Y en su dimensión prestacional, implica que como servicio público garantice que las prestaciones sean ofrecidas de modo ininterrumpido, constante e integral, debido a que está de por medio la protección de derechos fundamentales, como la vida, la integridad y la dignidad humana. De este modo, la protección real y efectiva del derecho a la salud se garantiza mediante prestaciones eficaces, regulares, continuas, oportunas y de calidad, que también sean, simultáneamente universales e integrales ${ }^{(4)}$.

Ello va acorde con lo que la Organización Mundial de la Salud (en adelante, OMS) estableció en 1942 sobre la salud definiéndola como un estado de completo de bienestar físico, mental y social, y no solamente la ausencia de afecciones o enfermedades. Asimismo, señalando que el goce del grado máximo de salud que se pueda lograr es uno de los derechos fundamentales de todo ser humano sin distinción de raza, religión, ideología política o condición económica o social"(5). De este modo, cuando el artículo 119 del Código Penal alude a la salud, se debe entender que abarca tanto a la salud física, como a la mental y a la social.

Ahora bien, respecto a la salud mental en específico, el TC ha desarrollado este derecho indicando que tiene 4 características al amparo de los dos instrumentos internacionales mencionados:

a) el derecho a la salud mental es parte integrante del derecho a la salud;

b) el derecho a la salud tiene como único titular a la persona humana;

c) el derecho a la salud mental tiene como contenido el derecho a disfrutar del mayor nivel posible de salud mental que le permita a la persona humana vivir dignamente; $y$,

d) la salud protegida no es únicamente la física, sino que comprende, también, todos aquellos componentes propios del bienestar psicológico y mental de la persona humana (...).

De este modo, el TC considera que el derecho a la salud mental es un derecho fundamental cuyo sustento se encuentra contenido en el principio-derecho de dignidad humana y en los derechos a la salud y a la integridad psíquica. Ello debido a que la preservación de la vida humana no se limita solamente a proteger la supervivencia biológica de la persona humana, sino que también se extiende a la posibilidad concreta de recuperación y mejoramiento de las condiciones de salud. Por ello, considerar al ser humano integralmente, como una unidad física y psíquica, es imperativo, en vista de cautelar su desenvolvimiento vital dentro de unas condiciones mínimas de dignidad(6).

(2) Expediente 2730-2006-PA/TC. Fundamentos 9 y 10.

(3) Expediente 2480-2008-PA/TC. Fundamentos 5, 6, 7.

(4) Expediente 2480-2008-PA/TC. Fundamento 8.

(5) OMS. Definición de Salud. Preámbulo de la Constitución de la organización Mundial de la Salud, que fue adoptada por la Conferencia Sanitaria Internacional, celebrada en Nueva York del 19 de junio al 22 de julio de 1946.

(6) Expediente 2480-2008-PA/TC. Fundamentos del 10 al 17. 
Así, teniendo presente que el derecho a la salud mental tiene por finalidad la protección de los derechos a la salud, a la integridad personal y a una vida en condiciones dignas, se puede enunciar el contenido de este derecho, en el siguiente sentido:

a) El derecho a acceder a tratamientos adecuados e idóneos, sean ellos de orden preventivo, curativo o paliativo, cuando las personas tengan problemas para disfrutar del más alto nivel posible de salud mental, tratamientos que deben formar parte del sistema de salud y seguridad social.

b) El derecho a que la atención médica sea integral, es decir, que comprenda todo cuidado, suministro de medicamentos, intervenciones quirúrgicas, prácticas de rehabilitación, exámenes de diagnóstico y seguimiento de los tratamientos iniciados, así como todo otro componente que los médicos valoren como necesario para el restablecimiento de la salud mental del paciente $(. .)^{(7)}$.

Por su parte, la OMS en el 2001 emitió un informe en el cual ahondó en el entendimiento sobre este pilar de la salud indicando que no existe un único criterio para definirla y que el concepto de salud mental abarca entre otros aspectos el bienestar subjetivo, la percepción de la propia eficacia, la autonomía, la competencia, la dependencia intergeneracional y la autorrealización(8).

\section{La Salud Mental en peligro como causal contemplada en el numeral 11 de la Guía Técnica}

Ahora bien, ya habiendo decantado en lo que deberá entenderse como salud y salud mental, es preciso traer a colación lo que en el año 2012 la "Guía Técnica y de Políticas para Sistemas de Salud" nuevamente a cargo de la OMS, señaló en relación con el aborto terapéutico.

Esta indicó que, si bien en la mayoría de los países se permiten el aborto para salvar la vida de la mujer embarazada, algunos países han reglamentado listas detalladas de lo que consideran que son condiciones médicas que ponen en peligro su vida. En ese sentido, la complejidad recae en que dichas listas pueden interpretarse restrictivamente o considerarse exhaustivas, cuando, por el contrario, apuntan a ilustrar las situaciones que se consideran una amenaza para la vida y no excluyen el criterio clínico de lo que es riesgoso para la vida de una mujer determinada. Por eso es esencial que los proveedores de los servicios de aborto estén capacitados, que los servicios estén disponibles y se conozca su existencia (OMS; 2012, pág. 92).
De este modo, es importante que se desarrolle con fundamento jurídico y científico el alcance que deberá darse al enunciado "amenaza de daño grave o permanente" a la vida o salud de la mujer gestante.

Al respecto, la Guía Técnica y de Políticas para Sistemas de Salud estableció que:

“(...) el cumplimiento de los derechos humanos requiere que las mujeres puedan acceder al aborto sin riesgos cuando está indicado para proteger su salud. Es ampliamente conocido que la salud física incluye condiciones que agravan el embarazo y aquellas agravadas por el embarazo. El área de la salud mental incluye la angustia psicológica o el sufrimiento mental causado, por ejemplo, por actos sexuales obligados o forzados y el diagnóstico de un daño fetal grave. También se toman en cuenta las circunstancias sociales de la mujer al momento de evaluar el riesgo para la salud" (OMS, 2012).

De hecho, ya que todos los países que son miembros de la OMS aceptan su descripción constitucional de la salud como "un estado de completo bienestar físico, mental y social, y no solamente la ausencia de afecciones o enfermedades", esta descripción de la salud completa está implícita en la interpretación de las leyes que permiten el aborto para proteger la salud de las mujeres (OMS, 2012).

En ese sentido, la salud de la mujer gestante puede ser afectada por diversas razones, y puede ser el embarazo en sí mismo el origen de la complicación, impidiendo un tratamiento oportuno o agravando una enfermedad preexistente (Barfield \& Warner, 2012). Por lo tanto, el entendimiento sobre la salud de la gestante deberá comprender no solo complicaciones físicas, sino las implicancias hacia la salud mental de la mujer, y no solo a patologías, sino que abarca a los riesgos de que su salud se vea afectada.

Y es que, debe tenerse en cuenta el ánimo no restrictivo de la Guía Técnica dirigido a la mayor protección de la vida y la salud de la mujer en situación de riesgo inminente. En efecto, según el médico Luis Távara Orozco,

(7) Ídem.

(8) OMS. Informe sobre la Salud Mental en el Mundo 2001. "Salud Mental: Nuevos conocimientos, nuevas esperanzas". Disponible en: https://www.who.int/whr/2001/es/ 
la causal número 11 se puso porque no debe haber una receta de cocina para esto. Si miramos la clasificación de la OMS, hay más de 4.000 enfermedades y éstas pueden afectar a la mujer durante el embarazo. Es decir, no existen sólo ni 10 ni 11 razones médicas que permiten a una mujer acceder al aborto terapéutico (PROMSEX, 2015).

De este modo, para solicitar y acceder a la interrupción legal del embarazo no es necesario que la gestante esté agonizando o esté en inminente peligro de muerte, sino que es suficiente con que exista amenaza de daño grave y permanente en su salud, y por salud, no debe enfocarse solo en la salud física sino en la mental. Tan es así que es indispensable que las mujeres que se encuentren gestando con complicaciones, reciban atención especializada tanto por parte de médicos como psicólogos y médicos psiquiatras y acceso a información adecuada, todo ello para contribuir a prevenir el daño grave y/o permanente en la salud mental de la mujer gestantes (Escriben, 2009, pág. 10).

\section{La Salud Mental y el Aborto Terapéutico en el marco de la CEDAW y el PIDCP}

Ahora bien, además de las consideraciones expuestas tenemos que el Pacto Internacional de Derechos Civiles y Políticos y su Protocolo Facultativo fueron aprobados por la Asamblea General de las Naciones Unidas el 16 de diciembre de 1966, las mismas que entraron en vigor el 23 de marzo de 1976. Para nuestro país el instrumento de ratificación del Protocolo fue depositado el 3 de octubre de 1980 y su entrada en vigor fue a partir de 1981.

De esta manera, el Estado peruano reconoce la competencia del Comité de Derechos Humanos para recibir y considerar comunicaciones de personas que se hallen bajo su jurisdicción y que aleguen haber sido víctimas de una violación de cualquiera de los derechos enunciados por el Pacto Internacional Derechos Civiles y Políticos. Así, el Dictamen emitido con la Comunicación 115/2003 del 24 de octubre de 2005, por este Comité ante el pedido efectuado por K.L. por la negativa del Estado peruano a prestarle servicios médicos relacionados a un aborto terapéutico, expresamente contemplado en el Código Penal, debe ser aplicado.

Este dictamen señaló que nuestro país resultó responsable por las violaciones a los artículos 2, 7, 17 y 24 del Pacto
Internacional de Derechos Civiles y Políticos, y tuvo como conclusiones que con el diagnóstico de que el feto era anencefálico correspondía que se interrumpiera su embarazo ${ }^{(9)}$. $Y$ es que el Comité observó que la denunciante acompañó una declaración médica que acreditaba que, debido a su embarazo, su vida se encontraba en riesgo. Además, producto de la gestación, quedó con secuelas psicológicas severas acentuadas por su situación de menor de edad, como lo estableció su diagnóstico psiquiátrico. De este modo, este hecho le implicó sufrimiento por haber sido sometida a tratos crueles, inhumanos y degradantes, así como que significó que el Estado intervenga en su vida privada de manera arbitraria. Por lo tanto, el Comité determinó que el Perú tenía y tiene la obligación de adoptar medidas para evitar que se cometan violaciones semejantes en el futuro.

Por otro lado, la Convención sobre la Eliminación de todas las Formas de Discriminación contra la Mujer (CEDAW) se ratificó el 4 de junio de 1982 y entró en vigor el 13 de octubre del mismo año. $Y$ el Protocolo Facultativo que permite acudir a dicha instancia y que obliga al Perú a cumplir con lo que se señale en sus dictámenes está vigente desde el 9 de abril de 2001.

Por lo tanto, es pertinente mencionar el caso de la peruana L.C. que fue presentado ante el Comité de la CEDAW debido a la negativa de los médicos de un hospital limeño a practicar un aborto terapéutico y efectuar la intervención quirúrgica en la columna vertebral a esta niña de 13 años quien fue violada sexualmente, tras haberse intentado suicidar lanzándose al vacío desde el techo de una casa. El retraso en la intervención quirúrgica privó a L.C. de la posibilidad de una recuperación en la movilidad de sus extremidades. En efecto, la incapacidad del sistema de salud peruano al no asegurar el acceso al aborto terapéutico, el mismo que

(9) "Artículo 7 Nadie será sometido a torturas ni a penas o tratos crueles, inhumanos o degradantes. En particular, nadie será sometido sin su libre consentimiento a experimentos médicos o científicos. (...)"

"Artículo 1.- Nadie será objeto de injerencias arbitrarias o ilegales en su vida privada, su familia, su domicilio o su correspondencia, ni de ataques ilegales a su honra y reputación. (...)"

"Artículo 24.- Todo niño tiene derecho, sin discriminación alguna por motivos de raza, color, sexo, idioma, religión, origen nacional o social, posición económica o nacimiento, a las medidas de protección que su condición de menor requiere, tanto por parte de su familia como de la sociedad y del Estado. (...)" 
es legal y constituye un servicio esencial para la mujer, vulneró el cumplimiento de sus obligaciones a la luz de este tratado.

Por ello, el Comité de la CEDAW determinó que el Estado peruano era responsable internacionalmente por las violaciones de esta Convención respecto al artículo 1, por haberse advertido discriminación contra la mujer; artículo 2, referido al acceso a la justicia y a la obligación del Estado de adoptar todas las medidas adecuadas para erradicar la discriminación contra la mujer; artículo 3, en relación con la garantía del pleno goce y ejercicio de sus derechos y libertades fundamentales; el artículo 5, referido a eliminar patrones socioculturales en los que prevalezcan las funciones estereotipadas de mujeres $y$, por último, el artículo 12 respecto al acceso a atención médica en condiciones de igualdad.

El Comité recomendó, de este modo, que el Perú entre otras medidas, establezca un mecanismo para el acceso efectivo al aborto terapéutico que garantice el derecho a la salud física y mental de las mujeres, y tomar medidas para las disposiciones pertinentes de la Convención y la Recomendación General 24(10) en relación con la garantía de los derechos reproductivos en los centros de salud.

Por lo tanto, conforme a todo lo explicado, nuestro país antes del caso de la señora Borgoño en el 2015, ya había sido encontrado responsable por no haber garantizado el acceso al aborto terapéutico en mujeres que encontraron en riesgo su salud tanto física como mental, por seguir con una gestación. Asimismo, el Estado ya tenía conocimiento de los alcances de la salud, la salud mental y la necesidad de tener y aplicar lo establecido en un protocolo institucionalizado para la intervención de abortos terapéuticos por los profesionales médicos en todas las entidades que brindaban servicios de salud. De hecho, particularmente, luego del caso L.C., se elaboró y aprobó la Guía Técnica a fin de dar cumplimiento a las exhortaciones del Comité CEDAW.

En ese sentido, concluimos que previamente a que la Clínica no tramitara la solicitud de la señora Borgoño con la evidencia médica, la Clínica no cumplió con la Guía Técnica, en tanto el médico tratante no evaluó cabal y suficientemente, la salud de su paciente antes de emitir la decisión de que su estado no calzaba en ninguna de las causales para la aplicación del aborto terapéutico.

Y cuando nos referimos a evaluar el estado de la paciente, nos referimos ciertamente a evaluar su salud tanto física, mental y social para justificar la solicitud de aborto terapéutico ante la Junta Médica. Recordemos que quien determina e informa la existencia de riesgos a causa del embarazo es el médico encargado apoyando su evaluación en evidencia médica acompañada con el análisis de la situación particular de cada mujer (Chávez, 2013, pág. 498), esto es disponibilidad de recursos, situación de violencia, vulnerabilidad, etc., como lo establece la OMS, la Constitución y el TC.

Por lo tanto, concluimos que debió activarse un protocolo establecido por la Clínica para abordar la situación de la señora Borgoño de manera diligente y acorde con las normas, en donde se le atienda y evalúe, rápidamente, su estado de salud física, mental y social, para que el médico tratante recién pueda decantar en una conclusión.

Asimismo, que luego de la evaluación de cada instrumento nacional e internacional a través de una interpretación armónica y garantista, teniendo un diagnóstico médico referido a la salud mental y que esta indicara que la paciente se encontraba en peligro de persistir con la gestación, resultaba suficiente para activar el procedimiento de aborto terapéutico. Pues como hemos podido desarrollar, se puede concluir que cuando la salud, en este caso, mental, se encuentra en riesgo, el supuesto calza en el numeral 11 de la Guía Técnica sin mayor cuestionamiento. En ese sentido, la autoridad administrativa también habría valorado más la salud física que la salud mental, al señalar que debía existir un diagnóstico físico para de alguna manera, se confirmara o no la afectación en la salud mental de la señora Borgoño.

De este modo, consideramos que, ante esta evidencia, la clínica denunciada a través del doctor Almeyda se encontraba en la obligación de evaluar el estado de la salud mental en el que se encontraba la paciente para luego informarle las implicancias que tendría el seguir con la gestación, a fin de que esta decida solicitar la interrupción de su embarazo con recomendación médica.

\section{Discriminación}

La señora Borgoño denunció que la clínica habría cometido un acto discriminatorio contra ella, debido al incumplimiento de las normas sobre el aborto terapéutico, su falta de celeridad para responder las solicitudes y la omisión de diligencia para evitar riesgos graves a su

(10) Recomendación General sobre la Mujer y la Salud que el 2 de febrero de 1999 indicó que el acceso a la atención de la salud, incluida la salud reproductiva, es un derecho básico previsto en la CEDAW. 
salud; además, devinieron en un acto discriminatorio porque en su condición de mujer, había sido violado su derecho a la salud sexual y reproductiva poniendo, además, en riesgo su vida. Sin embargo, la autoridad no se pronunció al respecto ni en la primera instancia como en la segunda.

Así, en la Resolución admisoria no se consideró la discriminación por razones de género como una presunta infracción a partir de la cual iniciarían la investigación. Y, por consiguiente, el motivo por el cual se sancionó a la clínica fue básicamente por la afectación a su salud mental, pues habiendo brindado evidencia médica no se hizo efectiva la tramitación de la solicitud, repercutiendo en continuar con su gestación cuando no era recomendable.

En ese sentido, creemos importante evaluar si la posición de la señora Borgoño tendría asidero, y determinar si es que la clínica realizó un acto discriminatorio a través de sesgos valorativos en relación con los estereotipos de género, y si debió ser sancionada a razón del artículo 38 del CPDC por discriminación, por no haber evaluado su salud mental y por no tramitar correctamente su solicitud de aborto terapéutico.

Al respecto, empezaremos guiándonos por lo establecido en la Constitución cuando dice que toda persona tiene derecho a la igualdad ante la ley y que nadie puede ser discriminado por motivos de origen, raza, sexo, idioma, religión y cualquier otro motivo de la misma índole. Vemos pues que la norma señala expresamente dos reconocimientos, de tener garantizada la exigencia de ser tratado en igualdad de condiciones que otra persona y la exigencia constitucional de no ser discriminado por las razones sostenidas.

Y ¿qué es la igualdad y qué es la discriminación según la Constitución? Respecto a la igualdad nuestro TC ha indicado que:

“(...) la igualdad consagrada constitucionalmente, detenta la doble condición de principio y derecho fundamental. En cuanto principio, constituye el enunciado de un contenido material objetivo que, en tanto componente axiológico del fundamento del ordenamiento constitucional, vincula de modo general y se proyecta sobre todo el ordenamiento jurídico. En cuanto derecho fundamental, constituye el reconocimiento de un auténtico derecho subjetivo, esto es, la titularidad de la persona sobre un bien constitucional, la igualdad, oponible a un destinatario." (11)

En ese sentido, se puede entender que la igualdad, además de derecho, es un principio. Es un derecho de carácter fundamental, pues es necesario para la subsistencia del ser humano y para la convivencia con su entorno social. Como derecho fundamental, impone la obligación a todas las personas, incluyendo al Estado a través de sus autoridades, a tratar bajo las mismas condiciones a todos quienes se encuentren en la misma situación de hecho (Indecopi, 2015, pág. 16). Y que como principio ordena que la igualdad sea lograda o maximizada en la mayor me dida posible.

Ahora, respecto a la discriminación se entiende a ella como la acción de distinguir, apartar, segregar, pero ¿por qué se mencionan a estos motivos en específico? Pues porque son motivos que históricamente se han utilizado por las sociedades para menoscabar a ciertos grupos poblacionales por considerarlos inferiores. Es decir, ciertos grupos que se consideraban mejores frente a otros por contar con un rasgo o cualidad considerada superior o preferida socialmente, negando el acceso a bienes, oportunidades y derechos a los otros. Es por ello que, la prohibición se encuentra dirigida particularmente a estas conductas propias de quienes no aprecian a los seres humanos por sus capacidades, valores y por su naturaleza, atentando directamente contra su dignidad como ser humano $\mathrm{y}$, por lo tanto, impidiendo la normal convivencia en sociedad ${ }^{(12)}$.

Pero, previamente a un análisis de cualquiera de las condiciones, causas o consecuencias de una conducta discriminatoria con relación al caso que nos apremia, es fundamental diferenciar los conceptos entre los cuales tenemos a los estereotipos y al prejuicio, a fin de entender la relación existente entre ellos con la discriminación. Primero, los estereotipos son el "conjunto comprimido de creencias consensuadas sobre las características de un grupo particular" (Montes, 2008, pág. 1), en otras palabras, constituyen formas de categorización social. Segundo, el prejuicio es definido como una actitud suspicaz u hostil hacia una persona que pertenece a un grupo, por el simple hecho de pertenecer a él, y a la que, a partir de esta pertenencia, se le presume la misma cualidad negativas que se adscriben a todo el grupo (Ministerio de Cultura, 2017).

De este modo, los estereotipos han sido a menudo conceptualizados como representantes del componente cognitivo del prejuicio, pues estos se encuentran

(11) Expediente 45-2004-PI/TC. Fundamento 20.

(12) Ídem. 
estrechamente vinculados. En efecto, el prejuicio es la "actitud negativa hacia un grupo social o hacia un individuo, considerando su pertenencia a dicho grupo" (Pancorbo et al., 2011, pág. 313). En ese sentido, tenemos que la discriminación es el trato desigual socialmente reprochable y jurídicamente sancionable hacia las personas y a ciertos grupos en situación de vulnerabilidad, sobre la base de prejuicios, los mismos que se sostienen en estereotipos. Por lo que con la prohibición de la discriminación se busca que ninguna persona sea apartada o menoscabada por presentar ciertas características y por pertenecer a un grupo determinado particularmente vulnerable.

\section{Discriminación por razones de género: la situación de las mujeres}

Con relación a las mujeres, los estereotipos pueden deformar la autoconcepción de las mujeres, devaluar sus atributos, características y actividades y, en definitiva, degradarlas. Así, los estereotipos son un reflejo de la subordinación histórica que padecen las mujeres. Las actitudes y características de lo femenino, aunque puedan ser valoradas "positivamente", suelen ser consideradas como inferiores a las actitudes y características de lo masculino. "Esa inferioridad causa y justifica la devaluación de las mujeres en todos los sectores de la sociedad, lo que puede resultar en discriminación" (Cardoso, 2015, pág. 35).

En efecto, los estándares de vestimenta y comportamiento que las cosifican y las construyen como sumisas, incompetentes o sexualmente provocativas se basan en la idea de su inferioridad. Los estereotipos que prescriben qué es, qué debe hacer y cómo debe comportarse una "mujer" les dificulta a las mujeres el desarrollo de un plan de vida relativamente autónomo y la formación de su autoconcepción como un individuo singular. De hecho, es frecuente que las mujeres asuman irreflexivamente estereotipos que contribuyen a su propia subordinación, reproduciendo el papel pasivo e inferior que se considera apropiado a su status. Así, "cuando los estereotipos se mezclan con prejuicios, y están generalizados, ponen muchas barreras a las mujeres y resultan en discriminación" (Cardoso, 2015, pág.35).

Ahora bien, es cierto que la posición de las mujeres en casi la totalidad de los países se encuentra aún en una situación de vulnerabilidad que merece ser atendida a fin de garantizar que se le considere y trate igual, simplemente, por el hecho de ser persona. Pero cuando nos referimos a igual no se pretende entenderla como igual irrestricta a los hombres, sino como persona que, presentando características y necesidades distintas, merece tener el mismo acceso y oportunidades para ejercer sus derechos y deberes en la sociedad.
De esta manera, es menester precisar que la igualdad no garantiza que todos los seres humanos sean tratados de la misma forma siempre y en todos los casos, puesto que la igualdad y la no discriminación se desprenden de la idea de unidad de dignidad y naturaleza de la persona. En efecto, la igualdad jurídica presupone dar un trato igual a lo que es igual y desigual a lo que no lo es. De modo que se afecta a esta no solo cuando frente a situaciones sustancialmente iguales se da un trato desigual (discriminación directa, indirecta o neutral, etc.), sino también cuando frente a situaciones sustancialmente desiguales se brinda un trato igualitario, lo que se conoce como discriminación por indiferenciación ${ }^{(13)}$.

Para ello, tenemos que reconocer la existencia de un grupo importante de seres humanos que ven postergados sus derechos todos los días, no solo por las situaciones generales que pueden afectar simultáneamente a hombres y niños, sino que el agravante de que esas violaciones se dan en función del sexo de las mujeres (Mantilla, 1996, pág. 97). De hecho, es amplia la literatura desde las ciencias sociales y desde el Derecho al respecto, por lo que podemos resumir la situación particular de las mujeres en el mundo con la siguiente afirmación: desde el momento en que se han producido documentos y organismos específicos para el tema de mujer es que se puede advertir la necesidad de evidenciar una situación particular en el mundo respecto a esta población. Asimismo, que al interior tanto del sistema universal como del sistema interamericano, puede concluirse que originalmente el tema de la mujer y sus derechos humanos no estuvo contemplado al momento de diseñar los documentos y organizaciones encargadas de la protección y promociones de los derechos humanos (Butegwa, 1993, pág. 81).

Y a propósito de esta realidad, es que el Estado peruano ha ratificado dos tratados internacionales, la CEDAW ya mencionada con anterioridad y la Convención Interamericana para Prevenir, Sancionar y Erradicar la Violencia contra la Mujer (en adelante, Convención Belem do Pará) que

(13) Expediente 2437 2013-PA-TC. Fundamento 6. 
entró en vigor el 4 de julio de 1996. De esta manera, sería ocioso debatir si las mujeres en su diversidad se encuentran o no aún en una posición de desventaja y subordinación, teniendo evidencia tangible de que, en efecto, la situación de mujeres y hombres no es igual.

Sobre lo particular, la CEDAW en su artículo 1 definió la discriminación hacia las mujeres como toda distinción, exclusión o restricción basada en el sexo que tenga por objeto o por resultado menoscabar o anular el reconocimiento, goce o ejercicio por la mujer sobre la base de la igualdad del hombre y la mujer, de los derechos humanos y las libertades fundamentales en los ámbitos políticos, sociales, cultural, etc.

Asimismo, el tratado en su artículo 2 dispone la obligación de los Estados de adoptar, por todos los medios, una política encaminada a eliminar la discriminación contra las mujeres, y señala que para ello deben adoptar todas las medidas legislativas y de otro carácter que sean necesarias para prohibir la discriminación contra las mujeres y para eliminar la discriminación hacia las mujeres que cometan todas las personas, organizaciones y empresas. $\mathrm{Y}$, por último, en su artículo 3 indica que deben actuar en todas las esferas para asegurar el pleno desarrollo de las mujeres y garantizarles el ejercicio y goce de sus derechos humanos y libertades fundamentales en igualdad de condiciones que a los varones.

Ante ello, el Comité de la CEDAW ha especificado en su Recomendación General 19, que la violencia contra las mujeres en virtud de su género es una forma de discriminación que impide el goce de derechos y libertades en igualdad de condiciones y, por tanto, se encuentra proscrita a razón de la CEDAW. En palabras de este Comité, la violencia proscrita por la CEDAW es aquella dirigida contra la mujer porque es mujer o aquella que la afecta en forma desproporcionada y, por tanto, se constituye también como una forma de discriminación. También, el Comité CEDAW en su Recomendación General 28, indicó que la CEDAW coloca un énfasis en la discriminación y violencia que ocurren contra las mujeres en virtud del género, es decir, por los roles, estereotipos y atributos que se les asignan e imponen socialmente. Es así que, la CEDAW especifica obligaciones de respetar, proteger y cumplir con el derecho a la igualdad y no discriminación de las mujeres, dentro de las cuales se encuentra también la eliminación de la violencia basada en género y la erradicación de los prejuicios y prácticas basadas en estereotipos de género (Valega, 2019, pág. 39).

En la misma línea, la Convención Belem do Pará estipula en su artículo 6 que las mujeres tienen el derecho de una vida libre de violencia, lo que implica el derecho a ser libre de toda forma de discriminación y el derecho a ser valorada y educada libre de patrones estereotipados de comportamiento y prácticas sociales y culturales basada en conceptos de inferioridad o subordinación.

Y por su parte, la Corte Interamericana de Derechos Humanos señaló en la sentencia del caso González y otras ("caso Campo Algodonero") v. México, sentencia del 2009, que:

"es posible asociar la subordinación de la mujer a prácticas basadas en estereotipos de género socialmente dominantes y socialmente persistentes, condiciones que se agravan cuando los estereotipos se reflejan, implícita o explícitamente, en políticas y prácticas, particularmente en el razonamiento y el lenguaje de las autoridades [...]."

Efectivamente, esa dinámica puede dificultar el ejercicio de derechos humanos y al acceso de justicia imparcial debido a muchos estereotipos y prejuicios sobre mujeres que denuncian haber sufrido algún tipo de violencia, como, por ejemplo: "la mujer mentirosa, la sexualmente disponible o la irracional". La discriminación que resulta de la asunción y el uso de estereotipos y prejuicios causa y justifica actos de violencia. Así, la violencia contra las mujeres es la manifestación de las relaciones de poder históricamente desiguales entre los sexos, ya que naturalizan su inferioridad y subordinación social. Las tradiciones según las cuales una mujer es considerada como inferior y subordinada a un varón, o que tienen funciones estereotipadas, perpetúan prácticas que conllevan violencia y coerción. Por lo que la violencia contra las mujeres es una forma de discriminación que dificulta el ejercicio de sus derechos y afecta su dignidad $^{(14)}$.

Efectivamente, la discriminación de género debe entenderse como la discriminación por razón de sexo o por la construcción social en torno al mismo, que vendría a ser el género. No cabe duda de que, el grupo históricamente relegado a una situación de vulnerabilidad es el de las mujeres y en ellas recae los actos discriminatorios que, precisamente, evita que esta población puede gozar y ejercer sus derechos en igualdad de condiciones. Esta discriminación obedece a percepciones sociales que han generado tratamientos

(14) Recomendación General 19 de la CEDAW. Considerando 11. 
sociales inequitativos entre hombres y mujeres, los mismos que han sido tolerados y, en el peor de los casos, reforzadas por el sistema jurídico (Ruiz, 1999, pág. 133).

Así, la limitación y subordinación de la mujer no depende esencialmente de las discriminaciones concretas, particulares, sino de la discriminación estructural que representa la articulación de un modelo global cultural, sociopolítico y normativo patriarcal (Suárez, 2002, pág. 62), es decir, una sociedad que se cimienta en la perspectiva de vida solo masculina invisibilizando a los otros grupos poblaciones.

\section{Discriminación en el consumo}

Ahora bien, el artículo 38 del CPDC indica lo siguiente:

"Artículo 38.- Prohibición de discriminación de consumidores

38.1. Los proveedores no pueden establecer discriminación alguna por motivo de origen, raza, sexo, idioma, religión, opinión, condición económica o de cualquier otra índole, respecto de los consumidores, se encuentren es tos dentro o expuestos a una relación de consumo.

38.2. Está prohibida la exclusión de personas sin que medien causas de seguridad del establecimiento o tranquilidad de sus clientes $\mathrm{u}$ otros motivos similares.

38.3. El trato diferente de los consumidores debe obedecer a causas objetivas y razonables. La atención preferente en un establecimiento debe responder a situaciones de hecho distintas que justifiquen un trato diferente y existir una proporcionalidad entre el fin perseguido y el trato diferente que se otorga."

De este modo, en el ámbito mercantil y de protección al consumidor, según lo desarrollado por el INDECOPI, se distingue los actos discriminación de los tratos diferenciados ilícitos, en el sentido que la autoridad ha establecido en permanentes decisiones, que la discriminación en el consumo se trata de la decisión del proveedor por impedir que una persona sea beneficiaria de sus servicios o productos a partir de una valoración subjetiva basada en motivos prohibidos señalados en la Constitución como la raza, sexo, idioma, la religión o motivos de la misma índole. Y, una conducta califica como trato diferenciado injustificado cuando, sin partir de una valoración subjetiva del consumidor, no se sustenta en una razón objetiva y razonable.

A mayor aunamiento, en comparación con el trato diferenciado ilícito, la discriminación también es una forma de trato desigual y trasgresión al derecho a la igualdad, pero con ciertas diferencias. En el trato diferenciado ilícito, la negativa al acceso de productos o servicios se debe a motivos simples pero injustificados, irrazonables o subjetivos. Mientras tanto, en la discriminación los motivos son reprochables por la sociedad, ya que subestiman las características de grupos humanos (mayoritarios o minoritarios) para convertirlos en seres inferiores, no dignos de contar con los mismos beneficios que otros. Es decir, "se establecen clases para dar preferencia, poder y derechos a unos grupos en perjuicio de otros, todo lo cual no resiste a una normal convivencia en sociedad" (INDECOPI, 2015, pág. 29).

Y en esa misma línea, la Defensoría del Pueblo ha definido la discriminación de consumo como "el trato diferenciado basado en determinados motivos prohibidos por el ordenamiento jurídico que tiene por objeto o por resultado la anulación o menoscabo en el ejercicio o goce de derechos y libertades fundamentales de una persona o de un grupo de personas" (Defensoría del Pueblo, 2007, pág.29).

De este modo, para que un acto sea considerado como discriminatorio deben concurrir estos tres elementos: i) un trato diferenciado o desigual, ii) un motivo o razón prohibida y iii) un objetivo o resultado.

\section{8. ¿Se discriminó por razones de género a la señora Borgoño?}

Teniendo claro ello, pasaremos a relatar las razones por las cuales la clínica se negó evaluar la salud mental y a no dar trámite a la solicitud de aborto terapéutico de la señora Borgoño. En primer lugar, en los descargos presentados por la clínica se indicó que la Guía Técnica no podía ser aplicada en todos los casos sin control alguno. Indicó, por consiguiente, que la finalidad debe ser utilizada solo de manera excepcional, siempre que el caso lo amerite. En segundo lugar, señaló que solo el médico tratante en base a su diagnóstico médico podrá sugerir a la gestante la posibilidad de interrupción voluntaria del embarazo.

Al respecto, podemos advertir que la clínica practicaba una visión restrictiva de la Guía Técnica al indicar que el médico tratante es el único que podría determinar la presencia de elementos o condiciones que puedan ameritar la interrupción del embarazo, dándole un carácter irrefutable a su decisión en caso indique que la gestante no se encuentra en dicha situación. No obstante, si bien la Guía Técnica en efecto, menciona 
que el procedimiento comienza con la información o sugerencia del médico a la gestante para que esta solicite la interrupción, también señala que la gestante puede solicitarlo en tanto no se encuentre de acuerdo con la conclusión de la Junta Médica.

Consideramos que esto es importante, pues una mujer gestante puede perfectamente, identificar que su embarazo le está afectando y poniendo en riesgo su salud o su vida y así decida interrumpirlo, es por ello que, existe la posibilidad de una solicitud de revisión de la decisión primigenia por parte del médico tratante. Es decir, que la mujer solicite la evaluación de su salud no debe ser tomado como un evento extraordinario que merece ser detenido o evitado, al contrario, si se interiorizara que el objetivo y la finalidad de la Guía Técnica es salvaguardar la salud y la vida de la mujer respetando su decisión de aceptar o no la interrupción, los procesos establecidos deben ser interpretados con la razonabilidad suficiente para lograr dicho fin, y se entendería que el carácter excepcional del procedimiento no tiene por qué significar que el papel de la gestante sea residual o nulo.

Por lo tanto, se evidencia a nuestro criterio, que la clínica al considerar que habría un descontrol sin la intervención irrestricta del médico tratante para gatillar el procedimiento establecido en la Guía Técnica, es un prejuicio derivado del estereotipo asignado a la mujer como madre antes que persona autónoma con la capacidad y libertad de solicitar la interrupción de su embarazo por cuestiones médicas. Es decir, se anula la voluntad de una mujer en el momento que "ya es madre".

En efecto, la creencia estereotípica de que "la maternidad es el rol y destino natural de la mujer" se traduce en una opinión generalizada de que todas las mujeres deben ser madres, sin que sean relevantes sus especificas capacidades reproductivas, circunstancias emocionales o prioridades personales (Cook \& Cusack, 2009, pág. 13). Este deber entonces, impide que se conciba la idea de separar a la persona-mujer de la maternidad, por lo tanto, habría que evitarse y controlar cualquier circunstancia que provoque la interrupción, máxime si es la propia mujer gestante quien lo decide.

En tercer lugar, la clínica señaló lo siguiente: nos resulta extraño al leer dicho certificado (psiquiátrico), cómo puede darse un diagnóstico tan certero luego de un día de evaluación. Es lógico saber que, si una paciente necesita terapia psicológica, esta requiera un tratamiento que toma cierto tiempo para poder establecer un diagnóstico certero. De la misma forma, nos resulta extraño conocer que la señora Borgoño tiene como antecedentes sintomatología depresiva desde los 21 años, cuando en su Historia Clínica no se cuenta con dicha información. No obstante, consideramos que, en el supuesto de haber requerido un tratamiento psicológico, el médico tratante pudo haberla derivado a la especialidad correspondiente y tratar de esta forma la depresión que presentaba, no siendo incluso dicho supuesto, un factor para considerar la interrupción del embarazo.
Sobre el particular, podemos advertir tres acciones estereotipadas. La primera es desvalorar el diagnóstico psiquiátrico por depresión de la señora Borgoño realizado por la doctora Rondón. La segunda es la de sostener que lo que presentó la señora Borgoño podía ser tratado a través de una terapia psicológica. Y tercero es la de aseverar que en caso tuviera depresión podría haber recibido tratamiento psicológico mientras seguía con el embarazo, porque esta condición no significaba un factor para su interrupción.

Nuevamente, nos encontramos frente a una férrea posición de negación respecto a la posibilidad de que una mujer podría resultar afectada en su salud mental por una gestación complicada y/o riesgosa, al punto de minimizar un diagnóstico psiquiátrico sosteniendo incluso que este puede tratarse con un psicólogo. Sin embargo, aunque lo psiquiátrico dista mucho de lo psicológico, esta concepción de que lo psicológico no es relevante en tanto pasajero, incide además de un desconocimiento de la salud mental, en que una mujer gestando debe mantener el embarazo ante cualquier evento que le pueda ocurrir a ella.

Finalmente, otro argumento que consideramos resaltante fue el siguiente: “(...) dado que esta particular situación, amerita un pronunciamiento de la autoridad que expidió la Guía, con la finalidad de definir el tratamiento de este tipo de situaciones, ya que optar por interrumpir un embarazo de manera arbitraria puede abrir la posibilidad a que muchas gestantes, cuando lo consideren necesario, puedan solicitar la interrupción de su embarazo, creando en todos los establecimientos de salud, públicos y privados, la obligación de atender tantos abortos de manera indiscriminada."

Al respecto, vemos que la clínica espera una lista taxativa de las causales para interrumpir el embarazo, que sean expresas para que, de tal modo, sea más restringida su aplicación, como una suerte de checklist que en caso no cumpla con un elemento, entonces no procedería la causal.

$Y$ en ese sentido, advertimos la noción que, de no tener una lista taxativa de causales, las atenciones de abortos terapéuticos serían arbitrarias, porque obedecerán a lo que la 
gestante "crea necesario". Ante ello decimos que la propia Guía Técnica estableció que toda interrupción por cuestiones médicas estaría basada en un diagnóstico, es decir, la atención de un aborto terapéutico se ejecuta luego de que los médicos lo han acordado a solicitud de la mujer gestante, evaluando la evidencia idónea de una afectación a su salud o por peligro de su vida. A su vez, consideramos que creer que se necesitaría un "control", porque de no existir las mujeres abortarían deliberadamente y de manera desenfrenada si es que no hubiera esta restricción o naturaleza excepcional del aborto terapéutico, es una percepción estereotipada y negativa de las mujeres porque con ello se reafirma la noción de disciplinarlas sus cuerpos impidiendo bajo cualquier motivo posible, que una mujer "se salga con la suya" sin importar el motivo del por qué se encuentra gestando.

Se logra advertir, por lo tanto, toda una elaboración de la clínica dirigida a interpretar la Guía Técnica basada en estereotipos de género que incidieron en este caso particular al negarle la posibilidad del aborto terapéutico a la señora Borgoño en:

(i) soslayar la participación de la gestante en los procedimientos de aborto terapéutico;

(ii) exigir actos heroicos a la mujer gestante por el simple hecho de estar embarazada;

(iii) inferir que la mujer mentía acerca de su condición y;

(iv) sobreponer el rol de madre en una mujer.

Sobre el particular, es preciso mencionar que, la decisión de L. C. vs. Perú, emitida por el Comité CEDAW, fue la primera en reconocer que la denegación de acceso a un aborto está relacionada con el estereotipo patriarcal que predica que las mujeres, antes que nada, son máquinas reproductivas que pierden titularidad plena de derechos al momento de embarazarse y, por tanto, la protección a toda costa de la vida prenatal toma prevalencia (Promsex, 2018, pág. 78).

En efecto, en dicha decisión, el Comité resaltó la obligación de los Estados de eliminar la discriminación contra la mujer en el ámbito de los servicios de salud, incluyendo aquellos que tienen que ver con la capacidad reproductiva. En esa medida, estableció que los Estados tienen que asegurar que aquellos servicios de salud, presentes en la legislación, puedan ser implementados mediante acciones ejecutivas y de política pública, incluyendo mecanismos judiciales efectivos en caso de incumplimiento(15).

Sin embargo, lo que constituye la parte más relevante de la ratio decidendi del Dictamen es que el Comité consideró que la decisión de posponer la cirugía por el estado de embarazo estaba dictada por un estereotipo en el que la protección del feto debía prevalecer por encima de la salud de la mujer, sobre la base de que la razón de ser de una mujer es la de convertirse en un instrumento de procreación (Promsex, 2018, pág. 77).

Ello resultó de importante relevancia tanto para nuestro país como para todos los Estados a la luz de los derechos humanos, pues era importante que se reconozca que la denegación de la posibilidad de interrumpir un embarazo es una forma más de discriminación basada en el género, a sabiendas de que lo que se esconde detrás de la ferocidad de impedir abortar, es la instrumentalización de los cuerpos de las mujeres y la imposición del rol de género que se asigna como principal labor y justificación de la existencia de las mujeres como el parir y el convertirse en madres, incluso si mueren en el intento o sus cuerpos apenas sobreviven. Por lo tanto, era necesario que se reconociera que L. C. había sido discriminada por su condición de mujer (Promsex, 2018, pág. 77).

De este modo, analicemos si estos estereotipos configuraron prejuicios que devinieron en un acto discriminatorio en el consumo a fin de poder concluir que la Clínica discriminó a la señora Borgoño en virtud de lo dispuesto en el artículo 38 del CPDC.

Antes de comenzar es preciso señalar que existe consenso en que, si bien el INDECOPI no ha tratado casos de discriminación por género (sexo), ello no significa que no se hayan producido, sino que muchas veces las prácticas discriminatorias pasan desapercibidas porque la víctima no las denuncia o porque no desea verse expuesta nuevamente a la humillación o al escarnio público (INDECOPI, 2015, pág. 20). Por lo cual, consideramos que resulta relevante que, a partir del presente caso, se pueda aportar al debate.

Ahora bien, para determinar si existe discriminación debemos considerar lo elaborado por nuestro $\mathrm{TC}^{(16)}$ en los casos en los que ha tenido que decidir si es que se encontraba frente a un caso de presunta vulneración al derecho a la igualdad. Esta

(15) Comité CEDAW, Comunicación 22/2009, L. C. vs. Perú, dictada el 4 de noviembre de 2011. 
elaboración consiste en un análisis para identificar la existencia de supuestos iguales sometidos a consecuencias jurídicas distintas, o si se ha dado un trato semejante en situaciones desiguales, lo cual se denomina término de comparación (tertium comparationis). Y para que un objeto, sujeto, situación o relación sirva como término de comparación es preciso que presente determinadas cualidades.

La primera de ellas es que la comparación se encuentre conforme al ordenamiento jurídico, es decir, que no ha de tratarse de un término de comparación que se encuentre prohibido. La segunda es que el término de comparación sea idóneo y esto hace referencia a la necesidad de que éste represente una situación jurídica o fáctica que comparta una esencial identidad, en sus propiedades relevantes, con el trato que se denuncia. Tal identidad no alude a la equivalencia de rasgos entre las dos situaciones que se comparan, sino al hecho de que se trate de situaciones que puedan ser jurídicamente equiparables, es decir que, entre lo que se compara y aquello con lo cual éste es comparado, ha de existir cualidades, caracteres, rasgos o atributos comunes.

Por ello, es tarea de quien cuestiona una infracción a dicho derecho proceder con su identificación, así como con la aportación de razones y argumentos por las que éste debería considerarse como un término de comparación válido e idóneo. Y, puesto que de la validez e idoneidad del término de comparación depende la determinación (o no) de una intervención al mandato de prohibición de discriminación, su análisis se presenta como previo a la determinación de su lesividad. Y la tercera, luego de haberse determinado el término de comparación (válido e idóneo), corresponderá someter la existencia del trato diferenciado al test de proporcionalidad, a efectos de evaluar su legitimidad. Es decir, la existencia de una relación de proporcionalidad entre los medios empleados y el fin a alcanzarse a través del trato diferente. El concepto de proporcionalidad sirve como punto de apoyo para otorgar la ponderación valorativa entre principios constitucionales en conflicto (García, 2008, pág. 117).

En ese sentido, tenemos que la situación de trato diferenciado o desigual que postula la señora Borgoño es el acceso diferenciado a la salud reproductiva que existe entre los hombres y mujeres, razón por la cual el término de comparación propuesto es el acceso a los servicios de salud reproductiva de la señora Borgoño ofrecidos por la Clínica. Dicho lo anterior, corresponde entonces analizar la validez e idoneidad del referido término propuesto.

En cuanto a la validez, estamos de acuerdo con que el acceso a los servicios de salud reproductiva son derechos humanos fundamentales relativos al libre ejercicio de la sexualidad y a la libre elección del número de hijos, al tratamiento de infertilidad y a la protección de la maternidad, que quedaron definidos como tales en la Conferencia Internacional sobre Población y Desarrollo de El Cairo en 1994. En efecto, a razón de lo establecido por los acuerdos en la Conferencia, eso derechos se basan en el reconocimiento del derecho básico de todas las parejas e individuos a decidir libre y responsablemente el número de hijos, el espaciamiento de los nacimientos y el intervalo entre estos, así como a disponer de la información y de los medios para ello, y el derecho a alcanzar el nivel más elevado de salud sexual y reproductiva. También incluye su derecho a adoptar decisiones relativas a la reproducción sin sufrir discriminación, coacciones ni violencia, de conformidad con lo establecido en los documentos de derechos humanos (Galdos, 2013, pág. 457). Entonces, tenemos que, en cuanto a la validez, el término de comparación se encuentra dentro del ordenamiento jurídico.

Respecto a la idoneidad, que se refiere al hecho de que se trate de situaciones jurídicamente equiparables, podemos indicar que el servicio de atención a la salud reproductiva de la señora Borgoño es equiparable a la situación que podría tener cualquier otro varón, ambos merecen que se atiendan sus complicaciones en igualdad de condiciones. $Y$ respecto a la proporcionalidad, se puede concluir que el trato diferenciado de atención a la salud reproductiva entre hombres y mujeres no es proporcional bajo ningún contexto, en el sentido que la capacidad de gestar no tendría por qué significar en la mujer un detrimento en la posibilidad de acceder libremente a la salud reproductiva que pudiere necesitar

Teniendo ello presente, empecemos por el primer requisito para que se configure la discriminación en el consumo, que es el de advertir un trato diferenciado o desigual. Para ello, debemos indicar que el servicio al cual debió tener acceso la señora Borgoño fue a la salud sexual y reproductiva, cuyos componentes van desde el servicio de información y acceso a métodos anticonceptivos o tratamiento para

(16) Expediente 5238-2011-PA/TC. Fundamento 5. 
las infecciones de transmisión sexual, hasta la prevención y tratamiento apropiado de la infertilidad o aborto seguro con el respectivo tratamiento de sus posibles complicaciones, entre otros más. Así, puede entenderse que los servicios de salud sexual y reproductiva están dirigidos y garantizados tanto para hombres como para mujeres, haciendo incidencia en que, por lógica, un grupo necesitará unos servicios en particular. De este modo, vemos que un aborto legal seguro forma parte de la salud reproductiva de la consumidora que ha decidió atenderse en la clínica, es decir, si bien la señora Borgoño decidió atenderse todo el proceso de gestación con miras a dar a luz en la clínica, también estaba contemplado como evento que conforma su salud reproductiva, un eventual legrado por un aborto espontáneo o la ejecución de un aborto terapéutico.

Respecto al motivo prohibido, tenemos que estamos frente a una razón expresa en la Constitución y en los instrumentos internacionales como hemos desarrollado en líneas anteriores, toda vez que, el ser mujer ha significado que la señora Borgoño no pueda acceder a atenderse su salud reproductiva en igualdad de condiciones. El género significó para la clínica que se le atienda de distinta manera, gracias a las cargas estereotípicas y los perjuicios que se le impuso al ser una mujer gestante. Finalmente, ello decantó en que la señora Borgoño no fuese atendida del modo en que debió ser atendida a efectos de considerar que su salud mental se vio afectada y que correspondió la interrupción de su embarazo por razones médicas.

Por lo antes expuesto, llegamos a la conclusión de que sí existió discriminación por razones de género por parte de la clínica, al tener claro que el género hace referencia al conjunto de atributos, actitudes y conductas que son culturalmente asignados, que definen el rol social de cada sujeto en función de su sexo (Pérez, 2006, pág. 11-12), y que la clínica actuó conforme a ello en detrimento de los derechos como consumidora de la señora Borgoño.

Su condición de mujer al ser capaz de gestar la puso en una situación distinta para la atención y goce de su salud sexual y reproductiva. Efectivamente, el rol preconcebido que tiene una mujer en esta sociedad es la de principalmente, ser madre, por lo que resulta altamente reprochable la interrupción de su embarazo. Esto no pasa con los hombres, quienes ven atendidos estos derechos sin riesgo alguno, de este modo, que la condición de mujer y cuerpo gestante signifique en la persona un factor para el detrimento de sus derechos reproductivos, es discriminación por razones de género.

Asimismo, lo que sucedió con la señora Borgoño fue que, el médico tratante no cumplió con evaluarle debidamente su salud, lo cual, de no haber sido por que acudió a otro centro de salud, habría conllevado a una completa injerencia sobre su voluntad de solicitar un aborto terapéutico. Es decir, el médico al no informarle que le correspondía un aborto terapéutico impidió que puede tomar una decisión respecto a su derecho de decidir o no trascender en la sociedad.

\section{Reflexiones finales}

La autoridad reconoció dos cosas, que el procedimiento de aborto terapéutico establecido en la Guía Técnica no fue cumplido por la clínica, y que era importante que esta diera trámite a su solicitud, debido a que la afectación a la salud mental de la señora Borgoño debió ser evaluada por el médico tratante. Sin embargo, era necesario que la autoridad sancione la falta de atención y evaluación de su salud mental por parte de la clínica, pues al no hacerlo contravino tanto la norma sectorial como el mandato constitucional e internacional sobre la salud mental en el marco de un aborto terapéutico.

Por otro lado, también era importante advertir que nos encontrábamos ante un caso de discriminación por razones de género, toda vez que las razones por las cuales la Clínica decidió no dar trámite a la solicitud se basaron en estereotipos de género, impidiendo el ejercicio de su derecho fundamental a la salud, en este caso, a tener acceso a la atención de su salud reproductiva. De este modo, debió también sancionar al establecimiento por haber ejercido estas prácticas que impidieron a la señora Borgoño al acceso del servicio.

Consideramos que hemos podido demostrar que la escasa comprensión de los operadores de salud de lo que implica la salud mental en el bienestar de la persona se agrava cuando se interseca con la discriminación por razones de género. $Y$ es que, sobre las mujeres ocurre una situación particular, como en el caso de la señora Borgoño. A ella no solo no se le evaluó la salud mental, sino que, a pesar de comprobar su afectación, no se consideró suficiente para soslayar el rol de madre impuesto por los estereotipos de género, lo que finalmente devino en discriminación en el consumo que impidió la atención de su salud reproductiva.

Reconocer que basarse en estereotipos de género conllevan a la comisión de conductas discriminatorias impulsará a 
que las demás autoridades y la sociedad, paulatinamente, adquiera el compromiso para desterrar estas prácticas y que la situación de vulnerabilidad de las mujeres por razones de género desaparezca.

\section{Referencias bibliográficas}

Barfield W. \& Warner L. (2012). Preventing chronic disease in women of reproductive age: opportunities for health promotion and preventive services. Preventong Chronic Disease, 9. DOI: http://dx.doi.org/10.5888/ pcd9.110281

Butegwa, Florence (1993). Derechos Humanos de la Mujer. Un desafío a la Comunidad Internacional de Derechos Humanos. Comisión Internacional de Juristas. La Revista, 50.

Cardoso Onofre de Alencar, Emanuela (2015). Mujeres y estereotipos de género en la jurisprudencia de la Corte Interamericana de Derechos Humanos. Eunomía, 9.

Chávez-Alvarado, Susana (2013). Aborto Terapéutico, Ausencia Injustificada en la Política Sanitaria. Rev Perú Med Exp Salud Pública, 30(3), pág. 494-499.

Cook, Rebecca; Arango, M \& Dikens, B (2009). Healthcare responsibilities and conscientious objection. International J Gynecol Obstet, 104(3), pág. 249-252.

Cook, Rebecca; Cusack, Simone (2010). Estereotipos de género: Perspectivas legales trasnacionales. (A. Parra, trad.) Bogotá: Profamilia Pensilvania.

Defensoría del Pueblo (2007). Discriminación en el Perú. Problemática, normatividad y tareas pendientes. Serie Documentos Defensoriales. Documento 2. Defensoría del Pueblo: Lima.

Escriben Pareja, Paula (2009). Aborto terapéutico y salud mental. Revista Justicia de Género. DEMUS, Estudios para la Defensa de la Mujer.

Galdos Silva, Susana (2013). La conferencia de El Cairo y la afirmación de los derechos sexuales y reproductivos, como base para la salud sexual y reproductiva. Rev Perú Med Exp Salud Pública, 30(3), pág. 455-460.

García Toma, Víctor (2008). El Derecho a la Igualdad. Revista Institucional, 8, pág. 109-127.
INDECOPI (2015). Discriminación en el consumo y trato diferenciado ilícito. Lima: Dirección de la Autoridad Nacional de Protección al Consumidor.

Mantilla Falcón, Julissa (1996). Los Derechos Humanos de las mujeres: algunas reflexiones. Agenda Internacional, 3(7), pág. 83-94.

Ministerio de Cultura (2017). Discriminación Étnico-Racial en medios de comunicación. Diagnóstico situacional. Ministerio de Cultura: Lima.

Montes Berges, Beatriz (2008). Discriminación, prejuicio, estereotipos: conceptos fundamentales, historia de su estudio y el sexismo como nueva forma de prejuicio. Revista electrónica de la Universidad de Jaén, 3, pág. 1-16.

Organización Mundial de la Salud (OMS) (2012). Aborto sin riesgos: guía técnica y de políticas para sistemas de salud (2da ed.). Montevideo: OMS.

(2001). Salud Mental: Nuevos conocimientos, nuevas esperanzas. (Informe sobre la Salud Mental en el Mundo).Ginebra: OMS

Pancorbo, Gina; Espinoza, Agustín y Cueto, Rosa María (2011). Representaciones estereotípicas y expresión del prejuicio en el Perú. Revista de Psicología, 29.

Pérez del Río, T (2006). Discriminación indirecta, acción positiva y transversalidad de género. AMIT.

Promsex (2019). ¿Cómo se está cumpliendo el protocolo del aborto terapéutico? Entrevista a Luis Távara Orozco Coordinador para los países de América del Sur de la Iniciativa FIGO "Prevención del Aborto Inseguro"; presidente del Comité de Derechos Sexuales y Reproductivos de la Sociedad Peruana de Obstetricia y Ginecología. Recuperado de https://promsex.org/como-se-esta-cumpliendo-elprotocolo-del-aborto-terapeutico/

Promsex (2018). L. C. VS. Perú. Memoria del litigio la disputa jurídica por el derecho al acceso al aborto legal de las niñas víctimas de violación sexual. Lima: Promsex.

Resurrección, Salomé (2017). La discriminación y algunas de sus calificaciones. Pensamiento Constitucional, 22 (22).

Ruiz Bravo, Patricia (1999). Una aproximación al concepto de género. Sobre género, derecho y discriminación. Lima: Defensoría del pueblo.

Suárez Llanos, Leonor (2002). Teoría feminista, política y derecho. Madrid: Dykinson.

Távara Orozco, Luis (2017). Objeción de conciencia. Simposio: Bioética y Atención de la Salud sexual y Reproductiva. Revista Perú Ginecología Obstetricia, 63(4), pag. 581-590.

Valega Chipoco, Cristina (2019). ¿Des-estereotipando el Derecho?: Análisis de la interpretación de la regulación de la publicidad comercial realizada por el INDECOPI en casos de publicidad cuestionada por contener estereotipos de género considerados discriminatorios contra las mujeres (Tesis de grado de Licenciado en Derecho). Pontificia Universidad Católica del Perú. 